\title{
The importance of listening to medical students' experiences when teaching them medical ethics
}

\author{
L W Osborne and C M Martin Austin Hospital/Repatriation General Hospital, Heidelberg
}

\section{Authors' abstract}

This paper describes the change of emphasis that occurred in the teaching of ethics to small groups of clinical students. Although the original focus of the course was on the analysis of ethical dilemmas associated with individual patients known to the students, it soon became evident that there were, for the students themselves, more fundamental ethical dilemmas in their new role as clinical students.

These included worries about how to respond when patients asked questions which their consultants had previously deceived them about, worries about inflicting pain on patients, as with intravenous cannulation, and the role of the medical student in the clinical team. We emphasise the need to explore student experiences as part of the process of ethics teaching.

\section{Introduction}

The many different ways of teaching ethics to medical students have been described in a symposium on teaching medical ethics reported in the September issue of the fournal of Medical Ethics (1). Some papers recognised that the teaching of ethics to medical students is not only about imparting factual information regarding the theories of ethics as applied to medicine but also about the exploration of personal value systems. Many of the programmes that were discussed in that symposium used the educational methodology of a series of didactic lectures, or seminars, in which a series of topics in medical ethics is presented for discussion and debate by both students and teachers.

One important contribution of that symposium was to highlight the different perceptions brought to ethics discussion groups by students and teachers. Thus Southgate and colleagues (2) described the importance of students choosing their own topics and describing clinical situations well known to them as a method for engaging their interest in ethical issues.

However, Calman and Downie (3) reported that students felt that they lacked sufficient experience to engage in discussion on ethical issues associated with

\section{Key words}

Teaching medical ethics. individual patients and that they also believed that some of the issues were irrelevant to them as students and that the issues would be resolved when they held consultant positions.

Some attempts have been made to discuss the ethical issues associated with being a clinical student through the incorporation of units on medical ethics into the clinical curriculum (4). Higgs (5) pointed out that in his small-group teaching a number of issues to do with the role and status of medical students often arose when discussing particular clinical cases.

In this paper we describe the change in emphasis that occurred in teaching ethics to small groups of clinical students. While the programme was focussed originally on the ethical dilemmas associated with particular patients, it became evident that there were many issues that the students wished to discuss about their own role in the teaching hospital setting. Many of these issues had not been addressed before and it was evident that the unresolved nature of the issues aroused great anxiety in the students. We believe that these issues have to be considered in any programme on teaching ethics to medical students.

This report does not claim to present a scientific evaluation of the teaching programme, but rather wishes to emphasise to both students and facilitators of other programmes in medical ethics, the great richness of experience, insight and discussion that can be obtained by considering medical students' real-life experiences in the teaching of medical ethics.

\section{A description of the programme}

The Austin/Repatriation Hospital Clinical School was considered to be innovative in its response to requests from students for additional teaching in ethics through the introduction of a series of tutorials in medical ethics which would focus on the real problems in clinical practice by using a case study approach.

The series of tutorials in ethics began from the initial position of providing an opportunity for fourth-year medical students to discuss ethical issues that were considered to be relevant to their future clinical practice. At the commencement of the series, it was anticipated that the tutorials would build upon the limited exposure to theoretical issues in medical ethics that the students had received as part of their pre- 
36 Teaching medical ethics: The importance of listening to medical students' experiences when teaching them medical ethics

clinical curriculum and upon the clinical competencies the students had acquired in their brief exposure to clinical practice in the hospital setting. The programme described took place in 1986 and 1987, during which 504 th-year students attended 11 sessions in 1986 and 36 students attended seven sessions in 1987.

The teaching programme consisted of one introductory lecture at the beginning of the 4th year to the whole student body. This dealt in a general way with a description of ethical theories and the relevance of their study for medical practice.

The students, who had already been allocated into groups of six for clinical teaching, were asked to meet once in the same group during the year for an ethics tutorial. The clinical school made it clear to the students that attendance was compulsory.

One student from each group was delegated to prepare a brief outline of a patient's clinical problems and the ethical issues raised by the treatment plans for those problems. This outline was available prior to the tutorial to allow the facilitators some time to reflect on the issues raised.

The group met to discuss the problem for approximately 50 minutes. Each case, with its treatment plans, was analysed and discussed, and ethical issues associated with similar cases were raised by the facilitators. There was a deliberate attempt to move the discussion from the issues associated with a particular patient to more general issues. By analysing the particular case against other situations, an attempt was made to develop consistency in ethical reasoning and to point out that there was a theoretical framework for the discussion of like cases beyond questions of personal preference.

At the end of the session one of the facilitators gave a brief overview, which considered how conclusions to act are reached by utilitarian or by duty-based reasoning. These theories were presented to describe the extremes of ethical reasoning in order to emphasise that each theoretical approach could be used to justify particular conclusions.

Most of the issues raised in the tutorials were concerned with the care of the teminally ill patient, questions regarding disclosure of medical information to patients and relatives, patient autonomy, consent, and the cost of care to the patient and to society. Other areas discussed frequently were AIDS testing without consent, confidentiality, euthanasia and the ethics of 'not for resuscitation' orders. While the ethical issues associated with the case study were always debated seriously and vigorously, with insight and from a theoretical point of view, the students seized upon the opportunity to discuss their emotional and philosophical reactions to the topics not from the point of view of their future role as consultants or general practitioners, but from their immediate concerns regarding the impact of the ethical issues under discussion on their role as medical students.

The facilitators, a medical administrator with training in medical ethics and a moral philosopher, were slow to understand what was occurring in the groups, but once they were able to articulate the need to discuss the ethical concerns of students, as students, and not as future practitioners, the groups took on a new dimension and vitality.

\section{The original aims of the programme}

The aims of the programme were:

(i) to alert the students to the subtleties and complexities of ethical reasoning;

(ii) to describe how the complex nature of decisionmaking processes in the hospital setting often involve data other than technical, medical or scientific information;

(iii) to make clear that there were a number of ways of analysing particular issues, and

(iv) to point out the importance of individual value systems, both of patients' and health professionals', in arriving at decisions.

The programme did not set out to provide a comprehensive course in ethics for the students, nor did it offer an alternative set of values or beliefs, and it did not seek to humanise the students. The limited objective as originally described was to heighten the students' consciousness of a variety of ethical issues and provide frameworks in which the students could analyse and defend a particular ethical position.

In the light of these aims, the course was indistinguishable from most others that have been described.

\section{Some student responses that changed the emphasis of the programme}

As the programme evolved, it became obvious to the facilitators that there were some particular ethical dilemmas associated with the role of being a clinical student in the setting of a major teaching hospital. These dilemmas were mentioned frequently and it became clear that each dilemma was associated with a significant degree of pain and anguish for the students. The students were keen to address these issues in preference to the theoretical considerations of how they might feel, respond or behave as fully qualified medical practitioners.

Among the more frequent examples of these dilemmas were:

(1) In a situation where a consultant will not tell his patient about the diagnosis or prognosis of his condition, and will not allow the patient to be given any information about his illness, the patient asks the student about his care. The student expressed real anxiety about this situation in the following ways:

(a) Is the student colluding with the consultant in not telling the patient?

(b) What does the student do or say when questioned by the patient? 
(c) Is a vague response to be viewed as a form of deception?

(d) How does this potential deception influence the student's working relations in the team setting?

(e) Is the consultant's control of the patient a metaphor for the consultant's control of the student as demonstrated by this control over information?

(2) A student, who attempts an invasive procedure on a patient, such as the insertion of an intravenous cannula or lumbar puncture is anxious about inflicting pain or distress unnecessarily.

(a) To what extent will this first experience of inducing pain influence the student's understanding of the morality of hurting one patient for the future benefit of many?

(3) The student is involved in the clerking and the care of a terminally ill patient. A number of particular anxieties are described as part of a general concern that the patient was subjected to unnecessary medical intervention.

(a) While the student is encouraged to consider herself as part of the medical team, she believes that such strenuous interventions are inappropriate, and yet cannot influence the management decisions.

(b) On the other hand, when there is a clear lack of intervention at the consultant's direction, and yet the student believes that some form of treatment would be appropriate from the point of view of her value systems, guilt feelings arise in the student about her complicity in the decision-making processes.

(4) In many areas of decision-making about patient care, the student believes that the doctor should have the final say in what treatment decisions are made. However, the student sees that nurses, social workers, and others have a significant input into treatment plans as part of the team approach to management. Again the student does not have the opportunity to have an input into these decisions about patient care.

(a) How is the student going to learn the skills necessary for making the right decisions in the team setting if he cannot participate actively in team meetings?

(b) How can the student's views on the clinical and technical grounds for decision-making be integrated with the social and philosophical issues espoused by non-medical team members?

(5) A student sees that most doctors consider the main criteria in considering the ethical aspects of treatment options as being related to the chances of the patient's survival and the usefulness of the patient's life. Issues of patient autonomy and self-determination are not often considered in determining individual treatment plans and this causes anxiety since: (a) The student believes in promoting the uniqueness $\frac{\text { TI }}{5}$ of each person and the capacity of each person to determine the nature of the care she receives.

(b) The student is aware of the costs of treatment $\overrightarrow{\bar{s}}$ decisions in a particular patient and yet these costso could dèny other patients any care at all.

\section{Discussion and conclusions}

From our experiences of this programme we concluded that the small-tutorial, group seminar based on the case-study method was successful as far as the initial. aims were concerned since it enabled a frank discussion $\vec{\overrightarrow{ }}$ to take place regarding important ethical issues. Thus ${ }^{\omega}$ the sessions were a useful learning experience for clinical students. However, facilitators of such groups $₫$ should be aware of, and be able to assist students to $\vec{r}$ articulate, the particular ethical problems related to $\vec{\omega}$ their experiences as students.

In our experience the case-study approach enabled 의 the students to see the theoretical relevance of ethical theory to decision-making in medical practice as well as 3 encouraging the students to attend classes in a topic which may not be seen to have immediate relevance in ${ }^{\supset}$ an already crowded medical curriculum. However, the $\overrightarrow{0}$ approach relied on undergraduate students projecting. their feelings, attitudes and behaviours to putative roles of consultant or general practitioner in order to determine how these individuals might, or should, respond to ethical dilemmas. Obviously the ability of students to analyse ethical dilemmas in these $\frac{2}{\circ}$ circumstances depended to a significant extent on their $\overrightarrow{\vec{A}}$ stereotyped models of medical practice.

The tutorial group was small enough to enable $\frac{3}{\sqrt{3}}$ competent handling of the emotional content of the discussion and the anxieties associated with any unresolved issues. The small group enabled the facilitator to keep the discussion 'on the track', while - providing an atmosphere for students to formulate and 3 . clarify their own behaviours and values. In addition the $\delta$ group provided a framework for students to analyse ethical problems by exposing them to variouso dilemmas, by asking them to discuss the possible alternatives to the situations in question and to evaluate을 different ethical theories.

As part of this process the students can be $\stackrel{N}{N}$ encouraged to examine their own value systems, to N delineate and describe complex problems, and to N develop listening and communication skills.

Finally, we concluded that there was a real need for informal opportunities for medical students to discuss $\frac{\text { }}{\varnothing}$ their concerns about ethical issues in medicine not only? in the abstract way of considering how they might 0 respond to issues in the future, but also in terms of the real dilemmas they face as students.

It is our hypothesis that an integrated theory and $\frac{\text { के }}{0}$ practice session in ethics emphasising present and $\frac{\Omega}{\sigma}$ future issues could lead to a maturation of moral reasoning. We also suggest that if medical students areo not given the opportunities to discuss and think through the anxieties associated with the ethical issueso 
38 Teaching medical ethics: The importance of listening to medical students' experiences when teaching them medical ethics

that directly affect them at an early stage in their clinical careers they will, as qualified medical practitioners, adopt stereotyped and limited responses to the ethical aspects of their work.

The important implications of analysing this programme for other teaching programmes are:

(i) that the real experiences of medical students can be used to explore ethical problems in medicine.

(ii) that medical students should be given the opportunity of discussing their concerns about the ethical aspects of treatment of particular patients, and of analysing their involvement with these patients. It became clear that, as the students spoke about their experiences of being medical students in major teaching hospitals, they confronted particular issues associated with the care of patients which they had not had the opportunity of discussing with faculty or hospital staff.

(iii) that students value a theoretical basis for the examination of ethical issues in medical practice. The students understood the need for a formal approach to the teaching of ethics that emphasised the basic principles and theory that could be applied to the analysis of complex clinical problems.

(iv) that the faculty conducting courses in ethics for medical students should be aware of the special concerns that students have about their roles in teaching hospitals.

(v) that support should be given to students who are aware and sensitive to the ethical issues associated with their role.

(vi) that small-group discussions provide an opportunity for the release of some of the tension associated with students' involvement in the ethical dimensions of the case studies.

\section{Acknowledgement}

We wish to thank Dr B Sweet, Associate Dean (Clinical), for his encouragement with the ethics teaching programme.

$L W$ Osborne, MB BS and C M Martin, MAPA, B Theol teach medical ethics at the Austin Hospital/ Repatriation General Hospital (Heidelberg).

\section{References}

(1) Gillon R. Medical ethics education. Fournal of medical ethics 1987; 13:115-116.

(2) Southgate L J, Heard S R, Toon P D, Salkind M R. A student-led approach to teaching. Fournal of medical ethics 1987; 13:139-143.

(3) Calman K C, Downie R S. Practical problems in the teaching of ethics to medical students. Fournal of medical ethics 1987; 13:153-156.

(4) Doyal L, Hurwitz B, Yudkin J S. Medical ethics and the clinical curriculum: a case study. Fournal of medical ethics 1987; 13:144-149.

(5) Higgs R. CABGs and KINGS: Relevance and realism in the teaching of clinical ethics in Camberwell. Fournal of medical ethics 1987 ; 132:157-159. 